\section{EDUCACÃ̃O}

V.7 $\cdot$ N.3 • Abril/Maio/Junho - 2019

ISSN Digital: 2316-3828

ISSN Impresso: 2316-333X

DOI: 10.17564/2316-3828.2019v7n3p67-82
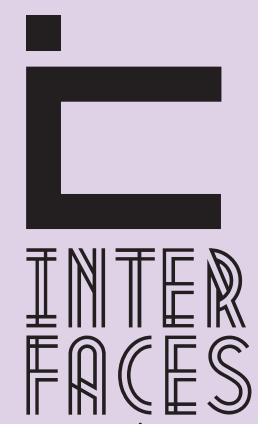

CIENTIFICAS

\title{
A VIVÊNCIA DE PROFESSORES COM ATIVIDADES DE MODELAGEM MATEMÁTICA: UMA PESQUISA À LUZ DA FENOMENOLOGIA
}

TEACHERS LIVING EXPERIENCE'S WITH MATHEMATICAL MODELLING ACTIVITIES: A RESEARCH IN THE LIGHT OF PHENOMENOLOGY

\section{LA EXPERIENCIA DE MAESTROS CON ACTIVIDADES DE MODELIZACIÓN MATEMÁTICA: UNA INVESTIGACIÓN LA LUZDE LAFENOMENOLOGÍA}

Bianca Martins de Oliveira ${ }^{1}$ Bárbara Nivalda Palharini Alvim Sousa² Rudolph dos Santos Gomes Pereira ${ }^{3}$

\section{RESUMO}

Este artigo apresenta uma pesquisa que tem por objetivo investigar a vivência de professores com atividades de modelagem matemática. Mediante uma investigação fenomenológica detalhamos a compreensão da interrogação: Como os professores de matemática, que atuam na Educação Básica da cidade de Cornélio Procópio, vivenciam a modelagem matemática? Os dados analisados foram coletados por meio de entrevistas semiestruturadas com os sujeitos da pesquisa. O fenômeno investigado foi evidenciado por meio da descrição fenomenológica e do destaque de unidades de significado. A pesquisa aponta núcleos de ideias que sinalizam o não uso de atividades de modelagem matemática em sala de aula. Fatores como conhecimento sobre a temática, participação em formação continuada e dificuldades entre teoria e prática são evidenciados no que tange à vivência de professores com a modelagem matemática.

\section{PALAVRAS-CHAVE}

Educação Matemática. Modelagem Matemática. Fenomenologia. Vivência de Professores. 


\section{ABSTRACT}

This paper presents a research that aims to investigate the experience of elementary and high school teachers with mathematical modelling activities. Through a phenomenological investigation, we delineate the question: How do mathematics teachers who work in the Basic Education of the Cornélio Procópio city living experiencing the mathematical modelling? Data analyzed were collected through semi-structured interviews with the research subjects. The phenomenon investigated was evidenced through the phenomenological description and the highlighting of meaning units. The research points to nuclei of ideas that signal the non-use of mathematical modelling activities in the classroom. Factors such as knowledge on the subject, participation in postgraduate courses, continuing education and difficulties between theory and practice are evidenced in what concerns the living experience of teachers with mathematical modelling.

\section{KEYWORDS}

Mathematics Education. Mathematical Modelling. Phenomenology. Living Experience of Teachers.

\section{RESUMEN}

En este artículo se presenta un estudio que tiene como objetivo investigar la experiencia de los maestros con las actividades de modelización matemática. Por medio de una investigación fenomenológica detallamos la comprensión de la pregunta: ¿Cómo los maestros que trabajan en la Educación Básica de la Ciudad de Cornélio Procópio experiencia la modelización matemática? Los datos fueron recolectados a través de entrevistas semiestructuradas con los sujetos de investigación. El fenómeno investigado se puso de manifiesto por la descripción fenomenológica y de realce de unidades de significado. La investigación señala núcleos de ideas que muestran que no señal utilizando actividades de modelización matemática en las aulas. Factores tales como el conocimiento sobre el tema, la participación en la formación continua y las dificultades entre la teoría y la práctica son evidentes en relación con la experiencia de los maestros con la modelización matemática.

\section{PALABRAS CLAVE}

Educación Matemáticas. Modelización Matemática. La Fenomenología. Experiencias de los Maestros. 


\section{INTRODUÇ̧̃̃o}

Na Educação Matemática é crescente na literatura publicações que tratam a respeito da modelagem matemática (KLÜBER, 2010, 2012; BIEMBENGUT, 2009; ALMEIDA; VERTUAN, 2014). São diversos os olhares sobre a temática e, diferentes pressupostos teóricos, deste modo, a modelagem matemática passou a ter entendimentos e perspectivas que por vezes são distintas (ALMEIDA; VERTUAN, 2011).

A consolidação da Modelagem Matemática na Educação Matemática se dá por meio de esforços de professores e pesquisadores que como sinalizam Almeida e Vertuan (2011, p. 19) "de alguma maneira, sinalizem que atividades de modelagem matemática podem atender interesses e necessidades da formação matemática dos estudantes na contemporaneidade”. No entanto, mesmo que os professores simpatizem com a modelagem matemática e reconheçam a "pertinência de atividades de Modelagem no currículo [...] identificaram possíveis obstáculos para sua implementação, sugerindo certa insegurança em relação ao tema” (BARBOSA, 2004, p. 2). Neste contexto, delineamos a interrogação que move esta pesquisa: Como os professores de matemática, que atuam na Educação Básica da cidade de Cornélio Procópio, vivenciam a modelagem matemática?

Temos o entendimento de que este fenômeno ocorre em diferentes níveis de escolaridade, em particular na Educação Básica. Para entender sobre o fenômeno e sua ocorrência utilizamos pressupostos teórico-filosóficos e metodológicos indicados na fenomenologia (HUSSERL, 2000, 2002; KELKEL; SCHÉRER, 1982; BICUDO, 2010, 2011; KLÜBER, 2012). Ao nos propormos analisar a vivência, adentramos no cenário filosófico, por meio de uma incursão na fenomenologia. Neste artigo, apresentamos os referenciais teóricos que fundamentam a investigação, os pressupostos metodológicos adotados, a análise dos dados coletados no desenvolvimento das entrevistas semiestruturadas, a discussão dos resultados e pesquisas, e contribuições para a modelagem matemática na Educação Matemática.

\section{SOBRE MODELAGEM MATEMÁTICA NA EDUCAÇÃO MATEMÁTICA}

No cenário nacional, há uma pluralidade de entendimentos acerca da modelagem matemática na Educação Matemática (KLÜBER, 2012; ALMEIDA; SILVA; VERTUAN, 2012; BARBOSA, 2001, 2004; BASSANEZI, 2002). Em meio as diversas concepções os autores Almeida, Silva e Vertuan (2012), entendem a modelagem matemática como uma alternativa pedagógica, em que por meio da matemática são abordadas situações-problema não essencialmente matemáticas. Nesse contexto, um modelo matemático pode ser uma representação expressa por meio de uma linguagem ou estrutura matemática em que a finalidade é descrever ou explicar a resolução da situação-problema inicial. Um modelo pode ser expresso por meio de um gráfico, tabela, desenhos ou expressões algébricas.

Para Barbosa (2001), a modelagem matemática é vista como um ambiente de aprendizagem em que os alunos são convidados a indagar e/ou investigar, por meio de matemática, situações da re- 
alidade. 0 autor também aborda a modelagem matemática na perspectiva sociocrítica (BARBOSA, 2006). Para o autor, modelo matemático pode ser "qualquer representação matemática de um fenômeno eleito para estudo” (BARBOSA, 2007, p. 3).

Um dos precursores da modelagem matemática no Brasil foi Rodney Bassanezi, como nos apresenta Biembengut (2009). Para Bassanezi (2002), a modelagem matemática pode ser considerada como um método científico, na pesquisa e como uma estratégia de ensino e de aprendizagem de matemática, nas salas de aula. $\mathrm{O}$ autor define a modelagem matemática como "a arte de transformar problemas da realidade em problemas matemáticos e resolvê-los, interpretando suas soluções na linguagem do mundo real” (BASSANEZI, 2002, p. 16). Nesse contexto, o autor define modelo matemático como "um conjunto de símbolos e relações matemáticas que representam de alguma forma 0 objeto estudado” (BASSANEZI, 2002, p. 20).

A literatura aborda, ainda, considerações a respeito do professor no âmbito da prática com atividades de modelagem matemática. De acordo com Almeida e Dias (2007, p. 265) “o contato dos professores com a modelagem matemática oferece subsídios para eles desenvolverem novos entendimentos sobre a Matemática e seu ensino o que pode ter impacto na sua prática de sala de aula”. Para investigar a interrogação de pesquisa utilizamos os pressupostos da fenomenologia que serão apresentados no item a seguir.

\section{O USO DA FENOMENOLOGIA NO ÂMBITO DA PESQUISA}

Em termos etimológicos, a fenomenologia é uma palavra "composta por fenômeno + logos. Fenômeno, cujo significado é o que se mostra, o que aparece, e logos, entendido como pensamento, reflexão, reunião, articulação", a "articulação do sentido do que se mostra, ou como reflexão sobre o que se mostra” e "o que se mostra está ligado ao mundo físico, fenomênico, mas também a subjetividade daquele a quem se mostra” (BICUDO, 2010, p. 29).

A Fenomenologia aceita a realidade do mundo; não a coloca sob suspeição, isto é, não duvida dessa realidade considerada fenomênica. 0 fenômeno é o que é visto disso que se mostra. Nós o compreendemos como o encontro entre quem olha com atenção e o que é visto. 0 olhar e ser visto é denominado por Husserl o par noesis-noema ${ }^{4}$. Quando nos referimos ao ato intencional chamamos noesis; e quando nos referimos ao que está enlaçado por esse ato noema. (BICUDO, 2010, p. 29).

Nesse contexto, temos o fenômeno e o sujeito. O fenômeno como já dito é o que se mostra e o sujeito é aquele que “[...] olha em direção ao que se mostra de modo atento e que percebe isso que se mostra nas modalidades pelas quais se dá a ver no próprio solo em que se destaca como figura de mundo" (BICUDO, 2011, p. 30).

4 Um exemplo trazido por Bicudo (2010) é sobre uma árvore. Ver a árvore é um ato da consciência, portanto intencional; trata-se da noesis; o visto, a árvore, é o noema. 
Para a investigação, primeiramente temos que dar atenção "às concepções concernentes à realidade do investigado" (BICUDO, 2011, p. 11). Neste contexto, a autora sinaliza que há dimensões ontológicas e epistemológicas do quê e do como se investiga, porém o ontológico e epistemológico não se separam já que as coisas se formam e se originam na medida em que ocorrem. "As dimensões podem se separar nos desdobramentos da compreensão do produzido, uma vez que este, o produzido, se deixa captar na teia de expressões cujos significados se configuram e iluminam conforme os contextos em que são olhados" (BICUDO, 2011, p. 13).

Podemos então destacar o produzido e os modos pelos quais se dá o conhecer pela linguagem, reunindo e separando aqueles significados e respectivas expressões, em regiões de conhecimento e em categorias de realidade ${ }^{5}$.

Nossa investigação se dá no sentido epistemológico, focando como a modelagem matemática é vivenciada pelos sujeitos investigados. Para sua realização é possível obter relatos e descrições das experiências vividas, tanto por meio de depoimentos falados, gravados e transcritos, ou até por meio de filmagens. Como essa pesquisa tem foco na epistemologia, corroboramos com Bicudo (2011, p. 26), o qual sinaliza que este fato solicita "atenção ao tempo vivido nas vivências dos sujeitos investigados".

A vivência não é entendida como algo dado, pois somos nós que penetramos no interior dela e que a experienciamos de maneira imediata. Para Bicudo (2011), a vivência, ou o experienciado, é percebida e refletida no fluxo dos atos da consciência. Segundo Bicudo (2011) a experiência vivida é o contato imediato com a vida,

[...] não se tratando de um conteúdo de experiência, mas do ato de vivê-la. No momento em que a experiência ocorre ela não é ainda refletida. Porém, pode se tornar foco a qual a reflexão se volta, abrindo, no fluxo do vivido, momentos de tomar ciência do vivenciado. (BICUDO, 2011, p. 33).

Segundo Bicudo (2011, p. 30) mundo-vida, traduzido da palavra alemã Lebenswelt é entendido como a espacialidade (modo de sermos no espaço) e temporalidade (modo de sermos no tempo) em que vivemos com outros seres vivos e a natureza. Quando a autora se refere ao mundo não é como uma coisa, mas como um espaço que vivemos e que se expande na medida em que o sentido de ações se faz para cada um de nós e para a cultura da comunidade.

Para Klüber (2012, p. 29) "na fenomenologia, a atitude assumida e a interrogação oferecem a direção da investigação. Portanto, não são aplicadas categorias fenomenológicas ao objeto, mas sim assumidas as consequências filosóficas de olhar a coisa-mesma, como ela se mostra".

Na Educação Matemática, há pesquisas nacionais que buscam maior aproximação com a abordagem fenomenológica (KLÜBER; BURAK, 2008; BICUDO, 2010, 2011, 2012; MOCROSKY, 2015) e no âmbito da modelagem matemática alguns autores têm adotado os pressupostos da fenomenologia em suas pesquisas (BICUDO; KLÜBER, 2011, 2013; BRITO; OLIVEIRA; MILANI, 2015; KLÜBER, 2012). Nessas pesquisas os autores assumem a postura fenomenológica ligada à filosofia e também às va-

5 Realidade conforme Bicudo (2011) é o que é constituída, revelada pela consciência do sujeito. 
riações no tocante à metodologia de pesquisa o que nos conduz aos aspectos metodológicos utilizados no desenvolvimento da pesquisa.

\section{ASPECTOS METODOLÓGICOS DA PESQUISA}

A pesquisa foi desenvolvida com professores de matemática que atuam em escolas da Educação Básica da cidade de Cornélio Procópio no segundo semestre de 2016. Para o desenvolvimento da fase empírica foi desenvolvido um roteiro para realização de uma entrevista semiestruturada. Este roteiro, composto por sete questões, nos auxiliou na investigação do fenômeno:

1) De modo geral, como são as aulas de Matemática que você leciona?

2) Você faz o uso de metodologias de ensino em suas aulas?

3) Que metodologias de ensino você utiliza?

4) Você utiliza como exemplos situações reais para trabalhar com conceitos matemáticos em suas aulas de Matemática? Se sim, de que maneira?

5) 0 que você entende por modelagem matemática?

6) Como se deu o contato com a modelagem matemática?

7) Você faz uso da modelagem matemática em suas aulas? Se sim, como? Se não, por quê?

Foram entrevistados vinte professores de Matemática, dados foram coletados por meio de gravação de áudio. Para utilização dos discursos, advindos da entrevista, elaboramos um termo de consentimento para o entrevistado, este termo nos permitiu usar os discursos para publicação e traçar o perfil do professor. Para manipulação dos dados coletados durante a entrevista, atribuímos um código para cada professor de P01 à P20.

\section{A ANÁLISE DE DADOS: EM BUSCA DA COMPREENSÃO DO FENÔMENO}

Para investigar a vivência dos professores, consideramos importante conheceros sujeitos da pesquisa, desse modo buscamos indícios para traçar o perfil dos entrevistados. Por meio do termo de consentimento conseguimos identificar que os professores lecionam, em média, para 25 alunos por turma. A quantidade de professores que lecionam apenas no Ensino Fundamental (sete professores), apenas no Ensino Médio (um professor) e nos dois níveis de escolaridade (doze professores). Cerca de $60 \%$ dos professores lecionam tanto Ensino Fundamental, quanto no Ensino Médio. A partir dos dados coletados, para olharmos para o fenômeno que se mostra duas ações foram tomadas: a transcrição das entrevistas, a fim de detalhar o discurso dos professores e a descrição fenomenológica a partir das entrevistas transcritas.

Os áudios das gravações da entrevista foram escutados repetidas vezes, para que fosse possível fazermos a transcrição do discurso dos professores. Nesse sentido ao transcrevermos os discursos passamos a ter um texto referente a entrevista de cada professor, com o discurso completo, porém na 
forma textual e não mais oral. A partir dessa etapa iniciamos as análises de acordo com as indicações de Bicudo (2011). Foi preciso realizar a descrição fenomenológica do percebido. De acordo com as indicações de Bicudo (2011, p. 38), é preciso fazer uma descrição do percebido, mas o pesquisador não faz uma descrição que diga "foi assim, mas conforme percebi, ocorreu de tal modo". A descrição é sempre explicitada pela linguagem e "por isso que solicita análise e interpretação efetuadas com o auxílio dos recursos hermenêuticos”.

As descrições se constituíram nessa pesquisa como os excertos das falas dos professores, durante a entrevista, que fizeram sentido aos pesquisadores no que tange à vivência com a modelagem matemática, a partir do que considerava cada questão delineada no roteiro de entrevista e visa mostrar as estruturas em que a experiência se dá, suas estruturas universais, buscando:

O rigor do pesquisador fenomenólogo se impõe a cada momento em que interroga o fenômeno e ao seu próprio pensar esclarecedor. Para tanto são básicos dois momentos: epoché, quando põe o fenômeno em suspensão, destacando-o dos demais co-presentes ao campo perceptual do pesquisador, e redução, quando descreve o visto, seleciona as partes da descrição consideradas essenciais do fenômeno. (BICUDO, 1994, p. 20, grifos da autora).

Das descrições do fenômeno, partimos para a primeira redução fenomenológica em que é possível destacar as unidades de significado. Para Bicudo (2011) as unidades de significado, são unidades que fazem sentido para o pesquisador, integram os sentidos colocados em evidência. A construção das unidades de significado é designada como o ponto de partida das análises. A partir delas "é possível construir uma rede de significados, com vistas às convergências para o estabelecimento do núcleo de ideias" (KLÜBER, 2012, p. 89).

Após a redução fenomenológica nos debruçamos nas análises ideográfica e nomotética: a análise ideográfica consiste em destacar das unidades de significado, indicando a estrutura dos discursos dos professores, participantes da pesquisa. A partir do percebido pelas unidades de significado, convergências e divergências no discurso dos sujeitos permitem a realização da análise nomotética que evidencia generalidades por meio das asserções e dos núcleos de ideias elaborados a partir da redução fenomenológica (BICUDO, 2011).

Ao ler as descrições com o olhar dirigido pela interrogação, a realização da análise ideográfica tem por objetivo trabalhar com as ideias individuas expostas nos discursos e apresentadas por textos descritivos (MOCROSKY, 2015). Desse modo, foram destacadas passagens das descrições nas quais as mesmas integram os sentidos colocados em evidência, o que é denominado na fenomenologia de unidades de significado. A construção das unidades de significado é designada como o ponto de partida da análise fenomenológica. Ao destacar as unidades de significado, buscamos interpretá-las tendo como base o contexto geral da entrevista. Para tanto foi necessário recorrer a dicionários (etimológicos, da língua portuguesa e filosóficos). A interpretação foi viabilizada pelo explicitar da compreensão da experiência em sua totalidade, isto é, a escola, a literatura e as palavras usadas pelos professores. 
A seguir, apresentamos um fluxograma com a codificação utilizada no processo de análise. Cada professor respondeu a sete questões e para as respostas à cada questão, de cada um dos 20 professores, foram destacadas unidades de significado numeradas de $1,2, \ldots, \mathrm{n}$.

Figura 1 - Codificação para a análise dos dados

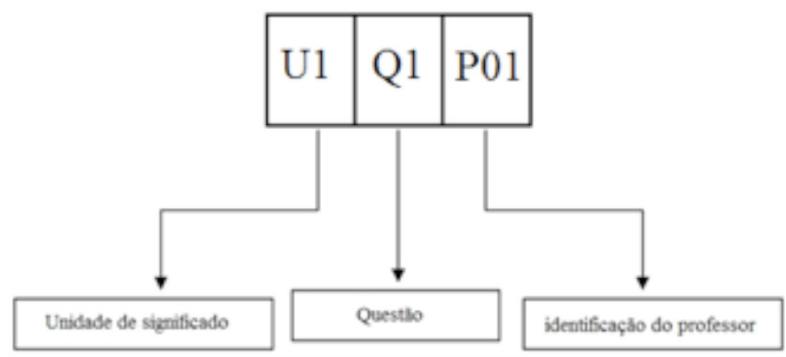

Fonte: Adaptado de Klüber (2012).

O código da Figura 1 se refere a identificação da unidade de significado extraída de cada resposta, de cada questão feita durante a entrevista a cada um dos professores (P01 à P20). Sinalizamos que pode haver mais de uma unidade de significado para a mesma questão, alterando assim o último número do código (U2.Q1.P01) significa que a resposta do professor para a questão um também se encaixa na segunda unidade de sentido.

A descrição fenomenológica resultou em 196 excertos advindos do discurso dos professores, após a primeira redução fenomenológica foram destacadas 153 unidades de significado. Este primeiro momento que destaca o individual é denominado 'análise ideográfica', a qual é elaborada por meio de um discurso na linguagem dos sujeitos, como pode ser visto nos trabalhos de Klüber (2008), Brito, Oliveira e Milani (2015). As convergências e divergências destas unidades de significado foram generalizadas em 32 núcleos de ideia.

Destacamos que, como sinaliza Klüber (2008, p. 91): “Esse procedimento não visa, de maneira alguma, mutilar ou separar, antes, visa distinguir para compreender melhor. É uma das maneiras de recorrer à estrutura formal da fenomenologia que visa à relação parte-todo".

Sobre o trabalho com análises nomotéticas, Bicudo (2011, p. 59) nos diz que:

Fenomenologicamente, indica a transcendência do individual articulada por meio de compreensões abertas pela análise ideográfica, quando devemos atentar às convergências e divergências articuladas nesse momento e avançar em direção ao seguinte, quando perseguimos grandes convergências cuja interpretação solicita insights, variação imaginativa, evidências e esforço para expressar essas articulações pela linguagem.

Nessa pesquisa, a análise nomotética consiste em evidenciar generalidades por meio das unidades de significado e dos núcleos de ideias elaborados a partir da redução fenomenológica (BICUDO, 2011). 
Por meio dos discursos descritos foram destacadas unidades de significado e analisando as convergências e divergências, que se trata da análise nomotética, foi possível elaborar os núcleos de ideias.

O núcleo de ideia é composto por unidades de significado reveladas pelo discurso. Por exemplo, podemos dizer que a questão de número seis trouxe-nos as respostas mais diversas. Ao analisarmos as unidades de significado, suas convergências e divergências, elaboramos nove núcleos de ideias. Esta gama de núcleos indica-nos que foram vários os modos como se deu o contato dos professores com modelagem matemática.

Os núcleos de ideias elaborados nesta pesquisa seguem o modelo da Figura 2, que representa um dos núcleos de ideia da sexta questão, este foi elaborado por meio das convergências de unidades de significados no quais os professores cursaram a disciplina de modelagem matemática no mestrado, como aluno regular ou aluno especial:

Figura 2 - Núcleo de ideias: cursou a disciplina de modelagem matemática no mestrado como aluno regular ou aluno especial

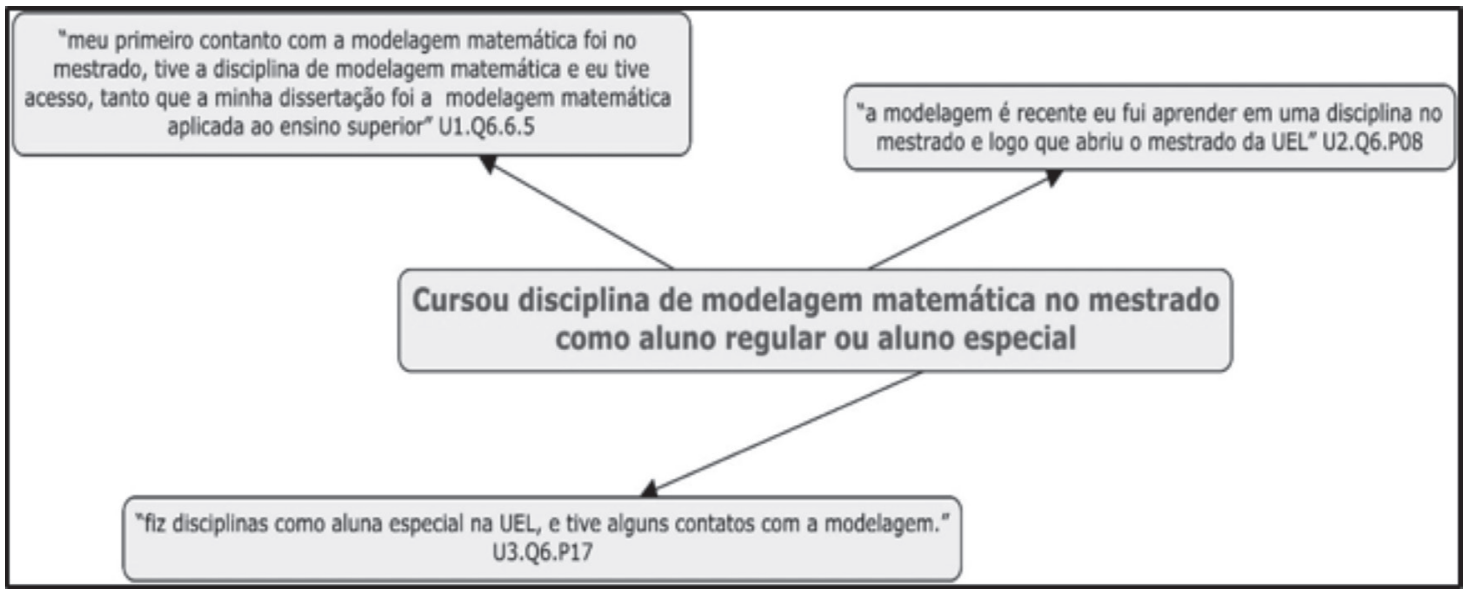

Fonte: Autores.

A disciplina de modelagem matemática não é ofertada nos cursos de mestrado das Universidades presentes em Cornélio Procópio. A Universidade Estadual de Londrina (UEL), Londrina, Paraná, é o local mais próximo de Cornélio Procópio, no qual há a oferta desta disciplina no programa de pós-graduação em Ensino de Ciências e Educação Matemática. Deste núcleo de ideias podemos sinalizar que três dos vinte professores entrevistados cursaram a disciplina de modelagem matemática no mestrado. Outro núcleo de ideia emergente, pode ser visto na Figura 3, em que foi elaborado devido a divergência existente dos demais discursos em resposta a questão 6: 
Figura 3 - Núcleo de ideia: eventos, congresso, encontros de educação matemática ou modelagem matemática

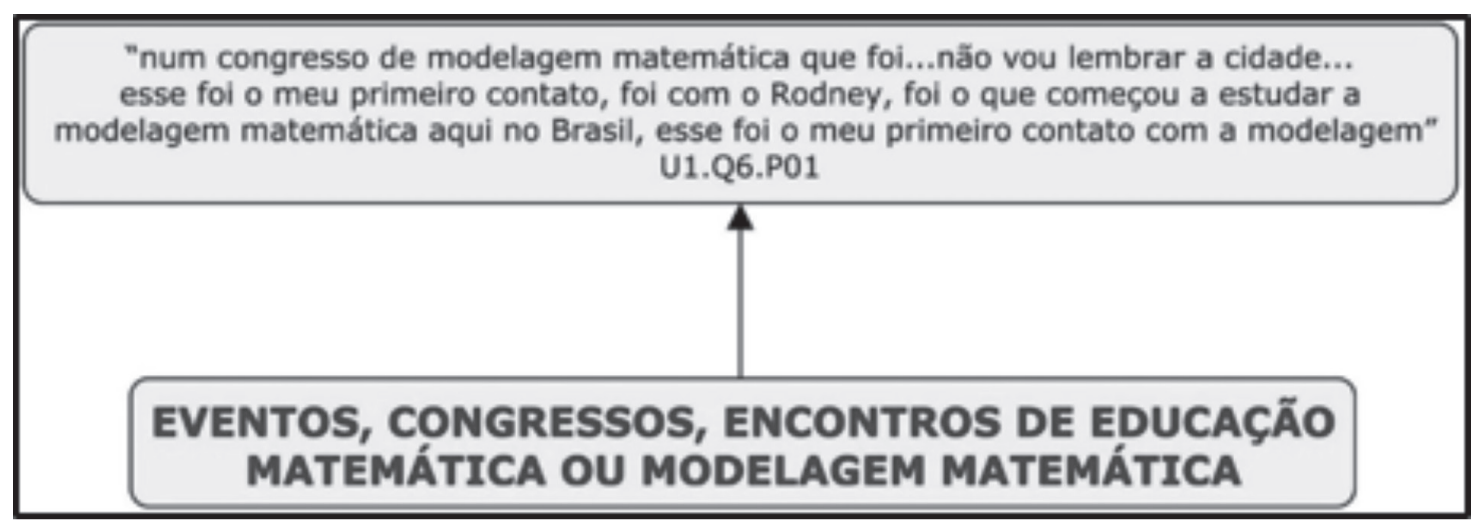

Fonte: os autores.

Este núcleo de ideia foi elaborado pelo fato de a unidade de significado U1.Q6.P01 divergir das demais unidades de significados destacadas nessa questão. 0 professor P01, foi o único professor que teve contato com a modelagem matemática por meio de um evento, participou do terceiro Encontro Paranaense de Modelagem na Educação Matemática (EPMEM), realizado no ano de 2006, na cidade de Guarapuava, Paraná.

Esta análise de convergências e divergências deu origem a 32 núcleos de ideias e em todos os casos elaboramos as figuras para sistematizar as unidades de significados e seus respectivos núcleos de ideias. Alguns resultados vislumbrados com a pesquisa são detalhados no próximo tópico.

\section{DISCUSSÃO DOS RESULTADOS}

Por meio da análise ideográfica destacamos 153 unidades de significado e com a análise nomotética foi possível contemplar 32 núcleos de ideias, elaboramos este metatexto que busca uma possível compreensão dos núcleos de ideias. Por meio dos núcleos de ideias, delineamos em sua totalidade um sentido para vivência de professores com a modelagem matemática.

As convergências das unidades de significado deram origem aos núcleos de ideias e por meio destes é possível sinalizar que, de modo geral, os professores têm um entendimento superficial a respeito da modelagem matemática. Isto pode ser percebido por meio da concentração de unidades de significado presente no núcleo de ideias: não faz o uso da modelagem matemática por falta de conhecimento. Este núcleo de ideia concentra 8 unidades de significado, que em sua maioria segue o exemplo da unidade: U1.Q7.P14 "não faço modelagem porque sinto que tenho que buscar mais conhecimento sobre atividades de modelagem”. 
Ao nos atentarmos para o inverso, quem faz o uso de modelagem matemática, percebemos que este público ainda é pequeno. 0 núcleo de ideias: faz o uso de modelagem matemática sempre que possível, revela que somente 6 dos vinte entrevistados já desenvolveram atividades de modelagem e usam sempre que possível em suas aulas.

Quando voltamos o olhar para o modo de como se deu o contato dos professores com a modelagem matemática, encontramos nove núcleos de ideias (Quadro 1). Este contato ocorreu das mais diversas formas:

Quadro 1 - Núcleos de ideias a respeito do contato dos professores com a Modelagem Matemática

\begin{tabular}{|c|}
\hline Aluno da disciplina modelagem matemática no ensino fundamental ou médio. \\
\hline Eventos, congressos, encontros de Educação matemática ou modelagem matemática. \\
\hline $\begin{array}{c}\text { Cursou a disciplina de modelagem matemática no ensino superior ou outras disciplinas em que foi } \\
\text { utilizada a modelagem matemática. }\end{array}$ \\
\hline Cursos de especialização em educação matemática e outras áreas ou cursos de capacitação. \\
\hline Curso de especialização ou capacitação em modelagem matemática. \\
\hline Cursou disciplina de modelagem matemática no mestrado, aluno regular ou aluno especial. \\
\hline Nunca teve contato com a modelagem matemática. \\
\hline Procurou saber por meio de pesquisas em livros, revistas, internet, dentre outros. \\
\hline Lecionou a disciplina de modelagem quando foi implementada ao currículo \\
de algumas escolas no ano de 2002.
\end{tabular}

Fonte: Autores.

Em meio aos nove núcleos de ideias foram revelados, pelas unidades de significado, as formas de vivência dos professores com a modelagem matemática. 0 percebido evidencia que apenas um professor fez mestrado na área de Educação Matemática cuja pesquisa foi realizada em modelagem matemática e três, incluindo este, cursaram a disciplina de modelagem matemática no mestrado como aluno especial.

Outros professores relataram ter conhecido a modelagem matemática na graduação ou na pós-graduação, mas nunca utilizaram a modelagem matemática em sala de aula, a vivência deles está mais associada com o que eles viram na graduação ou na pós-graduação, por exemplo, as unidades de significado: U1.Q6.P09 "meu primeiro contato foi com a pós-graduação [...] nós desenvolvemos atividades, fizemos pesquisas teóricas, mas eu ainda sei pouco, tinha as etapas mas eu não lembro certinho." U3.Q6.P01 “[...] na pós teve um trabalho de modelagem que eu fiz, acho que a gente modelou alguma coisa de uma fábrica de tecidos [...] e a gente teve que ir atrás dos dados”, mesmo vivenciando na especialização o professor não tem conhecimento a respeito de como lecionar vários conteúdos utilizando modelagem matemática. 
Outros professores que atualmente lecionam a disciplina de Matemática, não tem vivência com a modelagem matemática, mesmo partindo de situações reais para trabalhar conceitos em sala de aula, eles não conhecem se quer as tendências metodológicas de ensino que estão presentes nas Diretrizes Curriculares para o Ensino de Matemática (PARANÁ, 2008).

Outro ponto relevante do que foi destacado por meio das unidades de significado é a vivência dos professores com outras tendências metodológicos, sem ser a modelagem matemática, como por exemplo a resolução de problemas e as mídias tecnológicas.

E o que as revelações do fenômeno investigado nesta pesquisa implica para a modelagem matemática enquanto área de pesquisa? É relevante levantar a vivência dos professores de Cornélio Procópio, para que possamos entender o porquê professores que estão se formando agora não usam modelagem matemática em suas aulas, visto que a modelagem matemática é vivenciada na graduação. 0 que se mostra na essência do fenômeno é que os professores tiveram e têm oportunidades para conhecer a modelagem matemática, porém vivenciaram timidamente a experiência de trabalhar com a mesma seja no papel de aluno ou de professor.

\section{CONSIDERACÕES FINAIS}

Em busca da resposta à pergunta: Como os professores de matemática, que atuam na Educação Básica da cidade de Cornélio Procópio, vivenciam a modelagem matemática? As análises desenvolvidas indicam que há falta de professores capacitados em modelagem matemática, lecionando no Educação Básica. Dessa forma, é importante que o professor que deseja utilizar a modelagem matemática como alternativa de ensino possa vivenciar atividades na prática e não estar somente a par das teorias, ou seja, não se trata exclusivamente de saber, $m$ as sim, de aliar a teoria e a prática.

A investigação nos mostrou que os professores ao tentar inserir atividades de modelagem matemática em sala de aula se deparam com várias dificuldades, que podem estar relacionados com a imprevisibilidade de ações e reações dos alunos nas atividades, dúvidas dos professores sobre como fazer (inserir) modelagem matemática na sala de aula (BARBOSA, 2004), a falta de tempo para conduzir atividades desse tipo, estrutura curricular educacional particionada em disciplinas (BIEMBENGUT; FARIA, 2009), dificuldades essas que podem acarretar insegurança nos professores ao trabalhar com a modelagem matemática.

Neste sentido, Almeida Silva e Vertuan (2012) corroboram com apontamento no âmbito de formação, dizendo que é fundamental que seja estruturada uma formação docente em modelagem matemática a partir da tríade "aprender sobre”, "aprender por meio" e "ensinar usando" modelagem matemática. Só assim é possível ultrapassar a visão estritamente empirista e pragmatista da prática do professor em relação à modelagem, migrando para um terreno em que se aceita que o "como fazer" é impregnado de teoria e prática é que orientam o movimento do "conforto" para o "risco" (ALMEIDA; SILVA; VERTUAN, 2012, p. 24).

Por fim, sinalizamos a necessidade de uma formação continuada de professores que aborde a modelagem matemática e o diálogo frequente entre as instâncias universidade e escolas para que o compartilhamento de visões e experiências sejam feitos com mais constância. 


\section{REFERÊNCIAS}

ALMEIDA, L. M. W.; DIAS, M. R. Modelagem matemática em cursos de formação de professores. In: BARBOSA J. C.; CALDEIRA, A. D.; ARAÚJO, J. L. (org.). Modelagem matemática na educação matemática brasileira: pesquisas e práticas educacionais. Recife: SBEM, 2007. p. 253-268.

ALMEIDA, L. W.; VERTUAN, R. E.; Discussões sobre "como fazer" modelagem matemática na sala de aula. In: ALMEIDA, L. W.; ARAÚJO, J. L.; BISOGNIN, E. Práticas de modelagem matemática na educação matemática. Londrina: Eduel, 2011. p. 19-43.

ALMEIDA, L. W.; SILVA. K. P.; VERTUAN, R. E. A modelagem matemática na educação básica. São Paulo: Contexto, 2012.

ALMEIDA, L. W.; VERTUAN, R. E. Modelagem matemática na educação matemática. In: ALMEIDA, L. W.; SILVA, K. P. Modelagem matemática em foco. Rio de Janeiro: Ciência Moderna, 2014. Cap. 1. p. 1-19

BARBOSA, J. C. Modelagem matemática e os professores: a questão da formação. Boletim de Educação Matemática, Rio Claro, n. 15, p. 5-23, 2001.

BARBOSA, J. C. As relações dos professores com a Modelagem Matemática. In: Encontro nacional de educação matemática, 8, 2004, Recife. Anais [...], Recife: SBEM, 2004. 1 CD-ROM.

BARBOSA, J. C. MATHEMATICAL MODELLING IN CLASSROOM: A SOCIO-CRITICAL AND DISCURSIVE PERSPECTIVE. ZDM, 2006.

BARBOSA, J. C.; SANTOS, A. dos S. Modelagem Matemática, perspectivas e discussões. Encontro Nacional da Educação Matemática, 9, 2007. Anais [...], Belo Horizonte: SBEM.

BASSANEZI, R. C. Ensino-aprendizagem com modelagem matemática. São Paulo: Editora Contexto, 2002.

BICUDO, M. A. V. Filosofia da Educação Matemática segundo uma perspectiva fenomenológica. In: Filosofia da educação matemática: Fenomenologia, concepções, possibilidades didáticopedagógicas. São Paulo: UNESP, 2010. p. 23-47.

BICUDO, M. A. V. Pesquisa qualitativa segundo a visão fenomenológica. São Paulo: Cortez, 2011.

BIEMBENGUT, M. S. 30 Anos de Modelagem Matemática na Educação Brasileira: das propostas primeiras às propostas atuais. Alexandria: Revista de Educação em Ciência e Tecnologia, Blumenau, v. 2, n. 2, p.7-32, jul. 2009. 
BIEMBENGUT, M. S.; FARIA, T. M. B. Modelagem Matemática na Formação de Professores: Possibilidades e Limitações. Congresso Nacional de Educação, 9 - Encontro Sul Brasileiro de Psicopedagogia - EDUCERE, 3, Anais [...], Curitiba: PUCPR, 2009. p. 1 - 15.

BRITO, dos D. S.; OLIVEIRA, C. F.; MILANI, C. S. A ‘Escolarização’ do Espaço Vivido nas Atividades de Modelagem com Geometria: Uma Compreensão Sob a Perspectiva Fenomenológica. Seminário Internacional de Pesquisa em Educação Matemática - SIPEM, 6, 2015, Anais [...], Pirenópolis, Goiás.

HOUAISS. Dicionário eletrônico Houaiss da língua portuguesa [2009] CD-ROM.

HUSSERL, E. A crise da humanidade européia e a filosofia / Edmund Husserl; introd. e trad. Urbano Zilles. 2. ed. Porto Alegre: EDIPUCRS, 2002. 96p. Coleção Filosofia; 41.

HUSSERL, Edmund. A ideia da fenomenologia. Tradução Artur Morão. Rio de Janeiro: Edições 70, 2000. p. 20-80.

KAISER, G.; SRIRAMAN, B. A global survey of international perspectives on modelling in mathematics education. ZDM, v. 38, n. 3, p. 302-310, 2006.

KELKEL, A. L.; SCHÉRER, R. Husserl. Lisboa: Edições 70, 1982.

KLÜBER, T. E; BURAK, D. A fenomenologia e suas contribuições para a Educação Matemática. Práxis Educativa, Ponta Grossa, PR, v. 3, n. 1, p. 95-99, 2008.

KLÜBER, T. E. Uma metacompreensão da modelagem matemática na educação matemática. 2012. Tese (Doutorado) - Programa de Pós-Graduação em Educação Científica e Tecnológica, Universidade Federal de Santa Catarina, Florianópolis, SC, 2012.

KLÜBER, T. E. Modelagem Matemática: revisitando aspectos que justificam a sua utilização no ensino. In: Modelagem matemática uma perspectiva para a Educação Básica. Ponta Grossa: Editora UEPG, 2010. 97-114.

MOCROSKY, L. F. A postura fenomenológica de pesquisar em educação matemática. In: KALINKE, M. A.; MOCROSKY, L. F. (org.). Educação matemática: pesquisas e possibilidades. Curitiba: Ed. UTFPR, 2015. 192p.

PARANÁ. Diretrizes curriculares da educação básica do estado do Paraná: matemática. Curitiba: SEED, 2008. 


\section{Como citar este artigo:}

OLIVEIRA, Biana Martins de; SOUZA, Bárbara Nivalda Palharini Alvim; PEREIRA, Rudolph dos Santos Gomes. Interfaces Científicas Educação, Aracaju, v. 7, n. 3, p.67-82, abr. 2019. DOI: 10.17564 /2316-3828.2018v7n1p67-82 Acesso em: 24 mar. 2019.

1 Mestranda em Ensino de Ciências e Educação Matemática pela Universidade Estadual de Londrina - UEL.

E-mail: bianca_o.martins@hotmail.com

2 Doutora em Ensino em Ciências e Educação Matemática pela Universidade Estadual de Londrina - UEL; Docente do Colegiado de Matemática da Universidade Estadual do Norte do Paraná - UENP. E-mail: barbara.palharini@uenp.edu.br

3 Doutor em Educação pela Universidade Estadual Paulista "Júlio de Mesquita Filho" - UNESP; Docente do programa de Mestrado em Ensino e do Colegiado de Matemática da Universidade Estadual do Norte do Paraná - UENP. E-mail: rudolph.santos@uenp.edu.br. 
